\title{
Simple Modification in Wiring for Efficient Application of Arch Bar to Achieve Intermaxillary Fixation
}

\author{
Pawan Agarwal ${ }^{1}$ Rajeev Kukrele ${ }^{1}$ Dhananjaya Sharma ${ }^{2}$ \\ 1Plastic Surgery Unit, Department of Surgery NSCB Government \\ Medical College, Jabalpur, Madhya Pradesh, India \\ ${ }^{2}$ Department of Surgery, NSCB Government Medical College, \\ Jabalpur, Madhya Pradesh, India
}

Indian J Plast Surg:2021;54:99-100.

In maxillofacial fractures, it is most important to restore normal occlusion by intermaxillary fixation (IMF). Erich arch bars are most commonly used for achieving IMF because of their rigidity and versatility. ${ }^{1}$ To fix the arch bar to teeth, multiple wires need to be passed around the teeth and then two ends of the same wire (one end goes above and one end goes below the arch bar) are picked up and twisted firmly to secure the arch bar against the teeth. Multiple wire ends around the teeth look same and lie close to each other in a confined space creating confusion. One may pick up the end of the next wire and twist, which not only causes loosening of arch bar but also wasting of the next in line wire. This makes removal of two consecutive wires necessary. We describe a simple modification to identify the correct ends of the wire, in order to avoid confusion that reduces the application time of arch bar.

To fix the arch bar, 26-gauge stainless steel wires were passed from the mesial surface of a tooth to the lingual side and back on the buccal side, encircling the neck of tooth. In our method, the first wire was passed and one end of it was "circled." Then, the next wire was passed, and its one end was "bent." This was repeated till all wires were placed in position; now, on inspection, it was easy to recognize individual wires, as one end of the first wire was circled and the one end of next wire was bent; both being seen alternatively. As the sequence can be seen in -Fig. 1: straight-circled
Address for correspondence Pawan Agarwal, MS, MCh, FRCS, Plastic Surgery Unit, Department of Surgery NSCB Government Medical College, 292/293, Napier Town, Jabalpur, MP 482003, India (e-mail: drpawanagarwal@yahoo.com).

(1st wire), straight-bent (2nd wire), straight-circled (3rd wire), straight-bent (4th wire) (-Figs. 1, 2) Now, all wire ends are tightened together without confusion, and the arch bar is secured tightly in minimum time.

Arch bars are regularly used for the management of dentoalveolar and minimally displaced fractures of the maxilla or mandible, orthognathic surgeries, following tumor resection, and luxation or avulsion of teeth. The primary goal in management of maxillofacial fractures is to keep the reduced fracture segment stabilized by achieving dental occlusion. ${ }^{2}$

Many methods have been described in literature to achieve IMF such as Ivy eyelet wiring, Risdon wiring, arch bars, metal/acrylic splints, gunning splints, bonded brackets, and mandibulomaxillary fixation (MMF) screws. ${ }^{3}$ However, arch bar is the most popular method for achieving IMF as it provides good stability. ${ }^{4}$ The placement of arch bar is time consuming and difficult, as one has to operate in confined area, and presence of many wire ends close to each other create confusion for identification of right ends of each individual wire. This confusion in identifying individual wire could be avoided if wires were available in different colors, making their identification easy. However, wires are not available in different colors. Our simple modification of IMF technique allows easy identification of ends of each individual wire for twisting, reduces application time, and makes application of arch bar smooth. published online

February 22, 2021
DOI https://doi.org/

10.1055/s-0041-1723905 ISSN 0970-0358. (c) 2021. Association of Plastic Surgeons of India.

This is an open access article published by Thieme under the terms of the Creative Commons Attribution-NonDerivative-NonCommercial-License, permitting copying and reproduction so long as the original work is given appropriate credit. Contents may not be used for commercial purposes, or adapted, remixed, transformed or built upon. (https://creativecommons.org/licenses/by-nc-nd/4.0/).

Thieme Medical and Scientific Publishers Pvt. Ltd. A-12, 2nd Floor, Sector 2, Noida-201301 UP, India 


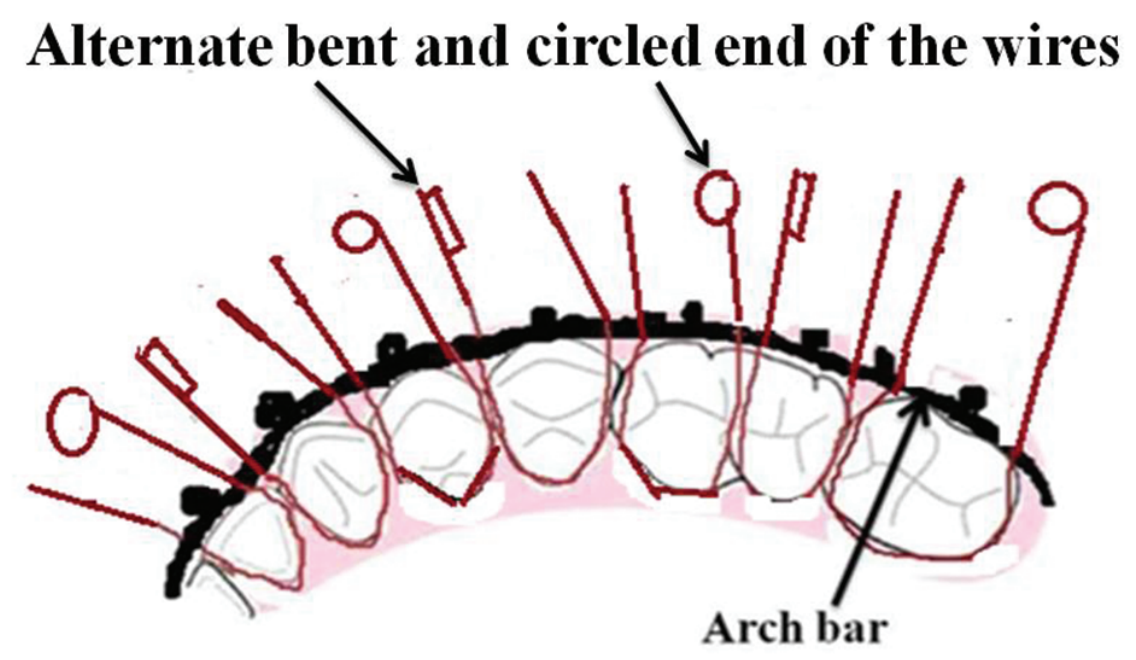

Fig. 1 Diagrammatic representation of alternate bent and circled wires.

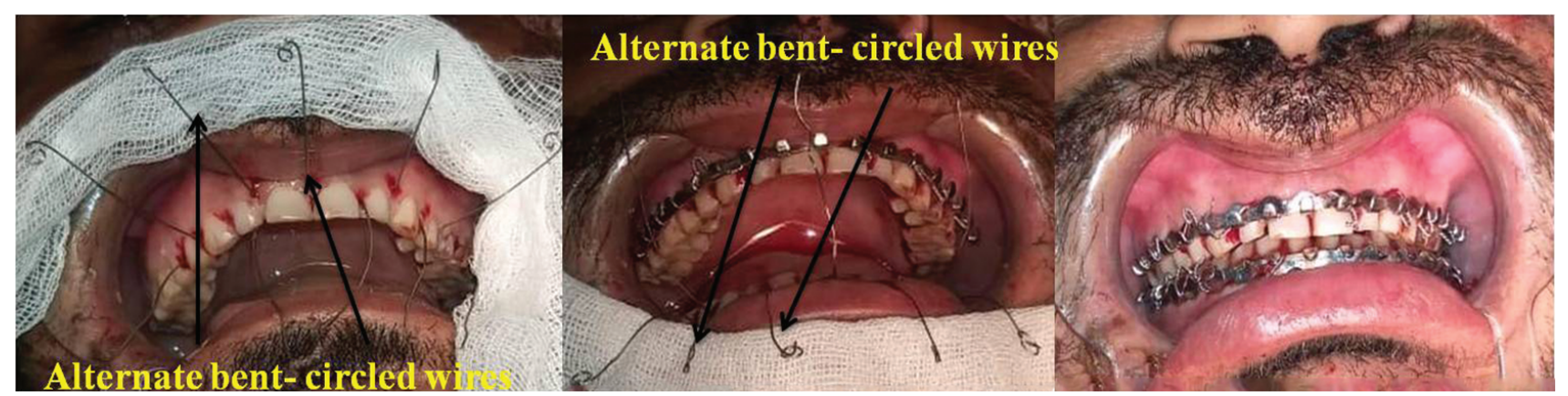

Fig. 2 Clinical picture of a patient showing alternate bent and circled wires while performing intermaxillary fixation (IMF).

\section{Source of Support}

Nil.

\section{Details of Earlier Presentation}

Not applicable.

\section{Statement of Institutional Review Board Approval} Obtained.

\section{Conflicts of Interest}

None declared.
2 Sharma M, Patil V, Singh R, Kulkarni S. Role of intermaxillary screw fixation in maxillofacial trauma: A prospective study. Int J Appl Dent Sci 2019;5:163-166

3 Balihallimath L, Jain R, Mehrotra U, Rangnekar N. To compare the efficiency of maxillomandibular fixation screws over Erich arch bar in achieving intermaxillary fixation in maxillofacial trauma: A clinical study. J Int Clin Dent Res Organ 2018;10:27-31

4 Baurmash H, Farr D, Baurmash M. Direct bonding of arch bars in the management of maxillomandibular injuries. J Oral Maxillofac Surg 1988;46(9):813-815

\section{References}

1 Ring ME, Harry N, eds. Dentistry - A Illustrated History 1992. New York: Abrahams Inc. Publishers; 1992:70 